\title{
Decreased expression of H3K27me3 in human ovarian carcinomas correlates with more aggressive tumor behavior and poor patient survival
}

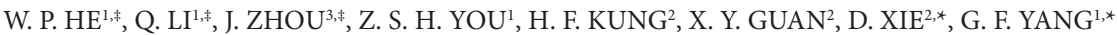

${ }^{1}$ Department of Gynecology, the First Affiliated Hospital, Sun Yat-Sen University, Guangzhou, China; ${ }^{2}$ State Key Laboratory of Oncology in South China, Cancer Center, Sun Yat-Sen University, Guangzhou, China; ${ }^{3}$ Department of Gynecology, the First Affiliated Hospital of Xiamen University, Xiamen, China

*Correspondence:pgf_yang@126.com,m,xied@mail.sysu.edu.cn

${ }^{*}$ Contributed equally to this work.

Received May 12, 2015 / Accepted July 27, 2015

\begin{abstract}
It has been confirmed that trimethylation of lysine 27 on histone $\mathrm{H} 3$ (H3K27me3) plays an important role in epigenetic process of tumorigenesis. However, the status of H3K27me3 in ovarian cancer and its impact on patients' clinicopathologic characteristics and prognosis are unclear. In the present study, the immunohistochemistry (IHC) was utilized to detect protein expression of H3K27me3 in 12 normal ovaries, 26 ovarian cystadenomas, 31 borderline ovarian tumors and 168 ovarian carcinomas by tissue microarray. The association between $\mathrm{H} 3 \mathrm{~K} 27 \mathrm{me} 3$ expression with clinicopathologic features and patient prognosis were also evaluated using various statistical models. The expression of H3K27me3 was decreased in 2 of 12 (16.7\%) cases of the normal ovaries, 8 of $26(30.8 \%)$ cases of cystadenomas, 12 of 31 (38.7\%) cases of borderline ovarian tumors, and 93 of $168(55.4 \%)$ cases of primary ovarian carcinomas, respectively $(P<0.05)$. Further correlation analysis suggested that decreased expression of $\mathrm{H} 3 \mathrm{~K} 27 \mathrm{me} 3$ in ovarian carcinomas was significantly correlated with more advanced pM and FIGO stages $(P<0.05)$. In addition, a significant association between decreased expression of H3K27me3 and shortened patient survival (mean 66 months versus 101 months, $\mathrm{p}=0.019$ ) was demonstrated by univariate survival analysis of the ovarian carcinoma cohorts. Importantly, H3K27me3 expression provided a significant independent prognostic factor in multivariate analysis $(\mathrm{p}=0.028)$. These findings confirmed that decreased expression of $\mathrm{H} 3 \mathrm{~K} 27 \mathrm{me} 3$ in primary ovarian cancer might be correlated with the acquisition of an invasive and/or aggressive phenotype of tumor, and might serve as an independent biomarker for poor prognosis in patients with ovarian carcinoma.
\end{abstract}

Key words: ovarian cancer, H3K27me3, protein expression, prognosis

Ovarian carcinoma is a major lethal malignancy in the women reproductive organs $(1,2)$. The disease has a steadily increasing incidence in Asian countries such as China and Singapore in recent years (3). Unfortunately, the long-term prognosis of patients with ovarian carcinoma remains unsatisfactory in spite of recent advanced surgical techniques and medical management. Although serum cancer antigen 125 (CA125) and ultrasonography are routinely used in diagnosis at present, unfortunately, they have relatively low sensitivity and specificity, and are not able to identify early stage ovarian carcinoma. Most patients with ovarian carcinoma are presented with advanced clinical stages (FIGO III/IV stage) and poor prognosis. The 5-year overall survival for patients with ovarian carcinoma is approximately $50 \%$ (4). Therefore, there is an urgent need to discover and identify the biomarkers for early tumor detection, prediction for biologic behavior and for the development of novel therapeutic targets, which is the critical first step towards improving the overall survival for women suffering from ovarian carcinoma.

Commonly, both genetic and epigenetic alterations are now thought to contribute to malignant transformation and progression (5). In addition, it has been discovered that epigenetic alterations, independent of DNA sequence, including DNA methylation and covalent histone modification, are involved in silencing of various tumor-suppressor genes and facilitating initiation and/or progression of human cancers (6-9). Histone methylation at key lysine or arginine residues has been shown to play an important role in acetylation and other modifications to provide a histone code that may determine heritable transcriptional states (9). H3K27 trimethylation is carried 
out by the enzyme EZH2, the catalytic subunit of Polycomb repressive complex 2 (PRC2) that interacts with target gene promoters, thereby ending with transcriptional repression (10). H3K27 trimethylation was found to contribute to the maintenance of cell identity, cell cycle regulation and oncogenesis (11-13). Recently, it has been found that H3K27me3 is increase expression in hepatocellular and esophageal cancers. On the contrary, H3K27me3 is decrease expression in prostate, breast, ovarian and pancreatic cancers. Aberrant expression of $\mathrm{H} 3 \mathrm{~K} 27 \mathrm{me} 3$ is thought to be important for initiation and progression with significant prognostic impact on these human cancers (14-18). However, the status of H3K27me3 expression and its clinical /prognostic relevance in ovarian cancer have not been fully elucidated.

In the present study, we detected the expression status of H3K27me3 in a large series of human epithelial ovarian tumors with normal ovarian tissues as controls using immunohistochemical (IHC) staining. The H3K27me3 IHC staining results were then correlated with a variety of clinicopathologic parameters and patient follow-up data. Our results should shed light in term of epigenetic regulation and biologic implication of $\mathrm{H} 3 \mathrm{~K} 27 \mathrm{me} 3$ expression in the development and progression of ovarian cancer.

\section{Patients and methods}

Patients and tissue specimens. In present study, the paraffin-embedded archival pathologic specimens from 237 patients with epithelial ovarian tumors (benign, borderline and carcinomatous), who underwent initial surgical resection between 1995 and 2007, were randomly collected from the archives of Department of Pathology, the First Affiliated Hospital, Sun Yat-Sen University, Guangzhou, China. These patients were selected based on the following factors: 1) complete clinical follow-up data is available for review; 2) without preoperative anticancer treatment. All patients with incomplete clinical follow-up data were excluded from the study. The ovarian tumor cohorts included 168 invasive carcinomas, 31 borderline tumors, and 26 cystadenomas. The age of patients with invasive carcinomas ranged from 25 to 82 years, with an average of 51.3 years. Clinicopathological data including

Table1. The expression of $\mathrm{H} 3 \mathrm{~K} 27 \mathrm{me} 3$ in normal ovaries and in benign and malignant epithelial ovarian tumors ${ }^{\mathrm{a}}$

\begin{tabular}{lcrc}
\hline & & \multicolumn{2}{c}{ H3K27me3 protein } \\
\cline { 3 - 4 } & All cases & $\begin{array}{c}\text { Decreased } \\
\text { expression }\end{array}$ & $\begin{array}{c}\text { Over } \\
\text { expression }\end{array}$ \\
\hline Normal ovaries & 12 & $2(16.7 \%)$ & $10(83.3 \%)$ \\
Cystadenomas & 26 & $8(30.8 \%)$ & $18(69.2 \%)$ \\
Borderline tumors & 31 & $12(38.7 \%)$ & $19(61.3 \%)$ \\
Invasive carcinomas & 168 & $93(55.4 \%)$ & $75(44.6 \%)$ \\
\hline
\end{tabular}

${ }^{a}$ Values are $\mathrm{n}(\%)$. A significant increasing frequency of low expression of H3K27me3 was observed in cystadenomas, in borderline tumors and in invasive carcinomas $(P<0.05$, Chi-Square Test for Trend). patient age; histological type; histological grade and FIGO stage were collected. These detailed clinicopathological characteristics were summarized in Table 2. In addition, as controls, another 12 normal ovaries removed for non-ovarian diseases are also collected. We obtained prior patient's informed consent and approval from the Institute Research Medical Ethics Committee of Sun Yat-Sen University.

Construction of tissue microarrays (TMA). The TMA was constructed in accordance with a previously described method (19). In brief, the individual donor paraffinembedded tissue blocks and the corresponding histological $\mathrm{H} \& \mathrm{E}$ stained slides were overlaid for TMA sampling. In our constructed ovarian tumor tissue-TMA, a 0.6-mm-diameter cylinder of tissue was removed triply in the representative tumor areas. Then, the tissue cylinder was re-embedded into a recipient paraffin block at a predetermined position. The tissues were sampled using a tissue arraying instrument (Beecher Instruments, Silver Spring, MD). Multiple sections ( $5 \mu \mathrm{m}$ thick) were cut from the TMA block and mounted on microscope slides.

Table2. Association of H3K27me3 expression levels with clinico-pathological features of ovarian carcinomas

\begin{tabular}{|c|c|c|c|c|}
\hline & \multicolumn{4}{|c|}{ H3K27me3 protein } \\
\hline & All cases & $\begin{array}{l}\text { Decreased } \\
\text { expression }\end{array}$ & $\begin{array}{c}\text { Over } \\
\text { expression }\end{array}$ & $P$ value $^{\mathrm{a}}$ \\
\hline Age at surgery (years) & & & & 0.484 \\
\hline$\leq 51.3^{\mathrm{b}}$ & 87 & $42(47.7 \%)$ & 45 (52.3\%) & \\
\hline$>51.3$ & 81 & $43(53.1 \%)$ & $38(46.9 \%)$ & \\
\hline Histological type & & & & 0.086 \\
\hline Serous & 113 & $56(49.6 \%)$ & $57(50.4 \%)$ & \\
\hline Mucinous & 21 & $15(71.4 \%)$ & $6(28.6 \%)$ & \\
\hline Others $^{c}$ & 34 & $14(41.2 \%)$ & $20(58.8 \%)$ & \\
\hline $\begin{array}{l}\text { Histological grade } \\
\text { (Silveberg) }\end{array}$ & & & & 0.399 \\
\hline G1 & 32 & $19(59.4 \%)$ & $13(40.6 \%)$ & \\
\hline G2 & 97 & $45(46.4 \%)$ & $52(53.6 \%)$ & \\
\hline G3 & 39 & $21(53.8 \%)$ & $18(46.2 \%)$ & \\
\hline pT status & & & & 0.363 \\
\hline pT1 & 47 & $26(55.3 \%)$ & $21(44.7 \%)$ & \\
\hline pT2 & 31 & $18(58.1 \%)$ & $13(41.9 \%)$ & \\
\hline pT3 & 90 & $41(45.6 \%)$ & $49(54.4 \%)$ & \\
\hline pN status & & & & 0.438 \\
\hline pN0 & 86 & $41(47.7 \%)$ & $45(52.3 \%)$ & \\
\hline $\mathrm{pN} 1$ & 82 & $44(53.7 \%)$ & $38(46.3 \%)$ & \\
\hline pM status & & & & 0.032 \\
\hline $\mathrm{pM} 0$ & 144 & $68(47.2 \%)$ & $76(52.8 \%)$ & \\
\hline pM1 & 24 & $17(70.8 \%)$ & $7(29.2 \%)$ & \\
\hline FIGO stage & & & & 0.010 \\
\hline I & 30 & $8(26.7 \%)$ & $22(73.3 \%)$ & \\
\hline II & 19 & $9(47.4 \%)$ & $10(52.6 \%)$ & \\
\hline III & 95 & $51(53.7 \%)$ & $44(46.3 \%)$ & \\
\hline IV & 24 & $17(70.8 \%)$ & $7(29.2 \%)$ & \\
\hline
\end{tabular}

${ }^{\mathrm{a}}$ Chi-square test; ${ }^{\mathrm{b}}$ Mean age; ${ }^{\mathrm{c} E n d o m e t r i o i d, ~ C l e a r ~ c e l l ~ a n d ~ U n d i f f e r e n t i a t e d ~}$ types 

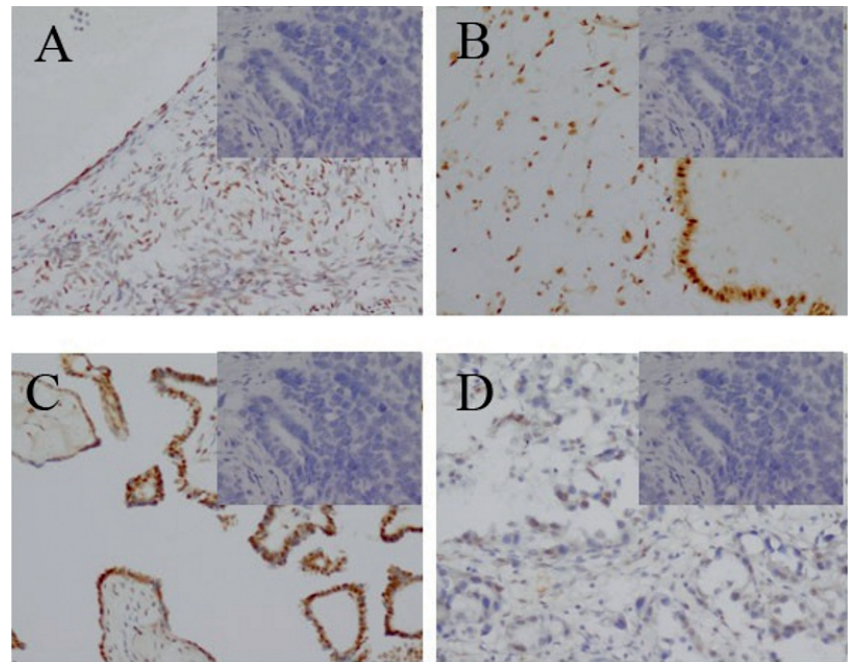

Figure1. Immunohistochemical staining of $\mathrm{H} 3 \mathrm{~K} 27 \mathrm{me} 3$ in human ovarian tissues. (A) High expression of $\mathrm{H} 3 \mathrm{~K} 27 \mathrm{me} 3$ was observed in a normal surface epithelium of ovary $(200 \times)$. (B) An ovarian cystadenoma showed decreased expression of H3K27me3 (200×). (C) Decreased expression of H3K27me3 was observed in a borderline ovarian tumor (200×). (D) Decreased expression of $\mathrm{H} 3 \mathrm{~K} 27 \mathrm{me} 3$ was detected in an ovarian carcinoma, in which more than $80 \%$ of carcinoma cells showed negative staining of H3K27me3 (200×). And the negative control picture with IgG was showed as an insert on the up right corner of each picture $(200 \times)$.

Immunohistochemistry (IHC). IHC studies were performed according to a standard streptavidin-biotin-peroxidase complex method as described previously (20). For antigen retrieval, tissue slides were microwave-treated and boiled for $3 \mathrm{~min}$ in a $10 \mathrm{mM}$ citrate buffer ( $\mathrm{pH}$ 6.0). Then, the slides were incubated overnight at $4^{\circ} \mathrm{C}$ in a moist chamber with rabbit monoclonal antibody anti-H3K27me3 (Cell Signaling Technology, Beverly, MA, USA, 1:100 dilution). A negative control was obtained by replacing the primary antibody with normal rabbit or mouse IgG. Known immunostaining positive slides were used as positive controls. As controls, 12 normal ovarian samples were also stained with the same antibody and staining protocol.

IHC evaluation. Protein expression levels of H3K27me3 were evaluated by microscopic examination of stained tissue slides. The presence of brown or yellowish brown granules in the nuclei with or without cytoplasmic brown granules were both considered to be positive for $\mathrm{H} 3 \mathrm{~K} 27 \mathrm{me} 3$ expression. A staining index (1-16) was obtained for each sample by multiplying the staining intensity (1-4; 1-negative, 2-week, 3 -moderate and 4-strong) with percentages of positively stained cells $(1-4 ; 1 \leq 10 \%, 2=10 \%-\leq 50 \%, 3=50 \%-\leq 75 \%$, $4=>75 \%$ ). Protein expression with a scoring index of $\leq 6$ is considered to be low or decreased (Fig.1D). The use of staining index of 6 as cutoff point to divide between positive and negative $\mathrm{H} 3 \mathrm{~K} 27 \mathrm{me} 3 \mathrm{IHC}$ staining results was based on the median of $\mathrm{H} 3 \mathrm{~K} 27 \mathrm{me} 3 \mathrm{IHC}$ staining results in ovarian epithelial tumors. The interpretation and scoring of $\mathrm{H} 3 \mathrm{~K} 27 \mathrm{me} 3$

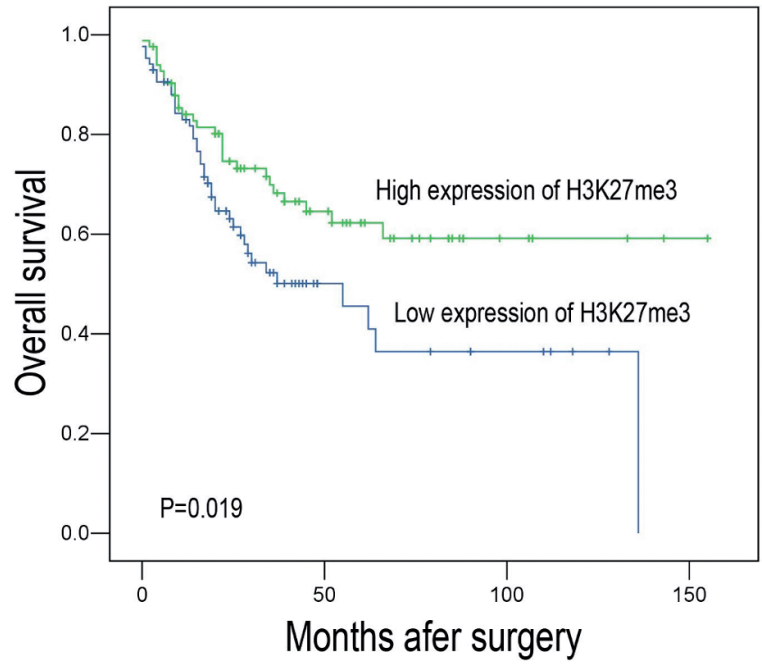

Figure 2. Kaplan-Meier survival analysis according to H3K27me3 expression in 168 patients with ovarian carcinoma (log-rank test).

Probability of survival of patients: decreased expression of H3K27me3, $\mathrm{n}=93$; high expression of $\mathrm{H} 3 \mathrm{~K} 27 \mathrm{me} 3, \mathrm{n}=75(P=0.019)$.

immunostaining were obtained by two independent pathologists, without prior knowledge of the identity of the samples.

Statistical methods. Statistical analysis was performed using SPSS software package (SPSS Standard version 13.0, SPSS Inc.). The correlation between $\mathrm{H} 3 \mathrm{~K} 27 \mathrm{me} 3$ expression and clinicopathological features of OC patients was evaluated by $\chi^{2}$-test. For univariate survival analysis, survival curves were obtained with the Kaplan-Meier method, and the differences in survival were determined by log-rank analysis. Multivariate survival analysis was performed using the Cox proportional hazards regression model. The results were considered statistically significant if the $P$-value was $<0.05$.

\section{Results}

H3K27me3 expression in ovarian tissues. According to the criteria described previously, decreased expression of H3K27me3 could be detected in 93 of 168 (55.4\%) cases of primary ovarian epithelial cancer. By contrast, decreased expression of H3K27me3 was only seen in 12 of 31 (38.7\%) cases of borderline ovarian tumors and 8 of $26(30.8 \%)$ cases of cystadenoma and 2 of $12(16.7 \%)$ cases of normal ovarian tissues, respectively $(P<0.05$, Table 1$)$. Representative IHC staining for $\mathrm{H} 3 \mathrm{~K} 27 \mathrm{me} 3$ was displayed in Figure 1.

Association of $\mathrm{H} 3 \mathrm{~K} 27 \mathrm{me} 3$ expression with ovarian carcinoma patient's clinico-pathologic features. The association between $\mathrm{H} 3 \mathrm{~K} 27 \mathrm{me} 3$ expression in ovarian carcinoma and several standard clinico-pathological features was further analyzed. The decreased expression of H3K27me3 was significantly higher in patients with more advanced $\mathrm{pM}$ stages $(P=0.032)$ and FIGO stages $(P<0.010)$ (Table 2$)$. No significant correlation was seen between $\mathrm{H} 3 \mathrm{~K} 27 \mathrm{me} 3$ expression levels and 
other clinicopathologic features, such as patient age $(\leq 51.3$ years $v s .>51.3$ years), tumor histological grade, $\mathrm{pT} / \mathrm{pN}$ stages and tumor histological types $(P>0.05$, Table 2$)$.

Relationship between clinico-pathologic variables, H3K27me3 expression and ovarian carcinoma patient survival: univariate survival analysis. In univariate survival analyses, cumulative survival curves were calculated by the Kaplan-Meier method. Differences in survival times were assessed using the log-rank test. In order to confirm the representativeness of the ovarian carcinoma cohort in this study, we analyzed established clinical prognostic factors of patient survival at first. We demonstrated a significant impact of well-known clinical pathological prognostic parameters, such as $\mathrm{pT} / \mathrm{pN} / \mathrm{pM}$ stages $(p<0.01)$ and FIGO stages $(p<0.001)$ on patient survival (Table 3 ). We further analyzed the impact of

Table 3. Clinical pathological parameters and expression of $\mathrm{H} 3 \mathrm{~K} 27 \mathrm{me} 3$ for prognosis of 168 patients with ovarian carcinoma by univariate survival analysis (log-rank test)

\begin{tabular}{|c|c|c|c|c|}
\hline Variable & All cases & $\begin{array}{c}\text { Mean } \\
\text { survival } \\
\text { (months) }\end{array}$ & $\begin{array}{c}\text { Median } \\
\text { survival } \\
\text { (months) }\end{array}$ & $P$ value \\
\hline Age at surgery (years) & & & & 0.866 \\
\hline$\leq 51.3^{\mathrm{a}}$ & 87 & 80.9 & 136.0 & \\
\hline$>51.3$ & 81 & 86.6 & 62.0 & \\
\hline Histological type & & & & 0.347 \\
\hline Serous & 113 & 76.1 & 62.0 & \\
\hline Mucinous & 21 & 70.9 & 45.0 & \\
\hline Others $^{c}$ & 34 & 85.3 & $\mathrm{NR}^{\mathrm{b}}$ & \\
\hline $\begin{array}{l}\text { Histological grade } \\
\text { (Silveberg) }\end{array}$ & & & & 0.127 \\
\hline G1 & 32 & 100.3 & 136.0 & \\
\hline G2 & 97 & 87.1 & 64.0 & \\
\hline G3 & 39 & 52.6 & 34.0 & \\
\hline pT status & & & & 0.008 \\
\hline pT1 & 47 & 108.0 & NR & \\
\hline pT2 & 31 & 83.6 & NR & \\
\hline pT3 & 90 & 69.2 & 36.0 & \\
\hline $\mathrm{pN}$ status & & & & $<0.001$ \\
\hline $\mathrm{pN} 0$ & 86 & 102.9 & 136.0 & \\
\hline $\mathrm{pN} 1$ & 82 & 51.2 & 25.0 & \\
\hline pM status & & & & $<0.001$ \\
\hline pM0 & 144 & 94.9 & 136.0 & \\
\hline pM1 & 24 & 22.4 & 9.0 & \\
\hline FIGO stage & & & & $<0.001$ \\
\hline I & 30 & 134.2 & NR & \\
\hline II & 19 & 113.1 & NR & \\
\hline III & 95 & 74.0 & 39.0 & \\
\hline IV & 24 & 22.4 & 9.0 & \\
\hline H3K27me3 expression & & & & 0.019 \\
\hline Decreased & 93 & 66.0 & 55.0 & \\
\hline Increased & 75 & 101.4 & NR & \\
\hline
\end{tabular}

H3K27me3 expression levels in ovarian carcinoma on patient survival. It showed that decreased expression of H3K27me3 was positively correlated with worse overall survival in patients with ovarian carcinoma ( $p=0.019$, Table 3 , Figure 2 ). The mean survival interval for patients with decreased expression of H3K27me3 was 66 months compared to 101 months for patients with overexpression of $\mathrm{H} 3 \mathrm{~K} 27 \mathrm{me} 3$.

Independent prognostic factors of ovarian carcinoma: multivariate cox regression analysis. Since features observed to have a prognostic influence by univariate analysis may covariate, we further analyzed clinical (pT/pN/pM stages, and FIGO stage) and molecular (H3K27me3 expression) variables that displayed significant impact on patient survival based on univariate analyses using Cox proportional hazards model (Table 4). We found that decreased expression of $\mathrm{H} 3 \mathrm{~K} 27 \mathrm{me} 3$ was an independent prognostic factor for adverse overall survival (relative risk: $0.604, \mathrm{CI}: 0.365-0.917, P=0.028$ ). In addition, the other clinical variables, such as $\mathrm{pN}$ status $(P=0.001)$ and more advanced FIGO stage $(P=0.017)$ were also found to be independent prognostic factors for overall survival.

\section{Discussion}

In recent years, the strategies for the treatment of ovarian cancer has been improved greatly, but the mortality of ovarian cancer is still high (2). The dismal survival for ovarian cancer patients is due to lack of detectable early symptoms and its insidious onset. Therefore, the identification of novel genetic biomarkers is of paramount importance because this would allow early detection of cancer, provide new therapeutic targets for cancer treatments, and ultimately improve overall survival for patients with ovarian carcinoma. In present study, we have identified that decreased expression of H3K27me3 can be used as a reliable and independent marker for predicting poor prognosis in patient with ovarian cancer.

Tumorigenesis is a complex process involving multiple factors and steps. Substantial evidence has demonstrated that both genetic (changes in DNA sequence) and epigenetic (heritable changes in gene expression process, independent of DNA sequence, including DNA methylation and covalent histone modification) changes (5), are critical in initiation and progression of a malignant phenotype. In recent years, epigenetic modification has been identified as a crucial phe-

Table 4. Multivariate analysis on overall survival (Cox regression model)

\begin{tabular}{|c|c|c|c|}
\hline Variable & Relative risk & 95\% Confidence interval & $P$ value \\
\hline $\mathrm{H} 3 \mathrm{~K} 27 \mathrm{me}^{\mathrm{a}}$ & 0.604 & $0.365-0.917$ & 0.028 \\
\hline pT status ${ }^{\mathrm{b}}$ & 1.352 & $0.881-2.075$ & 0.409 \\
\hline pN status ${ }^{\mathrm{c}}$ & 2.370 & $1.405-3.999$ & 0.001 \\
\hline pM status ${ }^{\mathrm{d}}$ & 1.371 & $0.380-4.951$ & 0.630 \\
\hline FIGO stage $e^{\mathrm{e}}$ & 2.942 & $1.209-7.159$ & 0.017 \\
\hline
\end{tabular}


nomenon in tumorigenesis (7). It is also known that epigenetic alterations in human cancer include changes in association with DNA hypermethylation within the CpG island and/or those in association with covalent modification of histones (acetylation of lysines, methylation of lysines and arginines, phosphorylations of serines and threonines, ADP-ribosylation of glutamic acids, and ubiquitination and sumolyation of lysine residues) $(9,21)$. Recently, the roles of epigenetic alterations of candidate proto-oncogenes and tumor suppressor genes in human cancer have become an intensive focus of study worldwide. The H3K27me3, one such modification, is required for Polycomb Repressive Complex 2 (PRC2) mediated repression of various genes essential for cell proliferation, cell differentiation and tumor development $(22,23)$. It has been shown that maintenance of the $\mathrm{H} 3 \mathrm{~K} 27$ me 3 mark during cell division is a crucial step for normal embryogenesis and cell identity (24). In human cancers, $\mathrm{H} 3 \mathrm{~K} 27 \mathrm{me} 3$ has been found to be involved in the development and/or progression of human cancers, and be evaluated as a prognostic factor in hepatocellular, prostate, breast, ovarian, pancreatic and esophageal cancers (14-18). However, some of the results are totally contradictory. In the present study, we investigate the expression dynamics of H3K27me3 and its clinicopathological/prognostic significances in patients with ovarian carcinomas.

Our results showed that the protein expression levels of H3K27me3 were high in normal ovary tissues. By contrast, in our cohorts of ovarian tumor specimen, the frequency of decreased expression of H3K27me3 was significant higher than that in normal ovary tissues. Significantly, further analysis demonstrated that the decreased $\mathrm{H} 3 \mathrm{~K} 27 \mathrm{me} 3$ protein expression was found to be correlated closely with the presence of distant metastasis $(p=0.032)$, and more advanced FIGO stages $(p=0.010)$. In addition, we found that $\mathrm{H} 3 \mathrm{~K} 27 \mathrm{me} 3$ expression or its function in ovarian carcinoma may represent an acquired molecular mechanism, by which, cancer cells are more prone to distant metastasis rather than local invasion. Previous study has found that, during cancer progression, aggressive tumor cells may have acquired this signature either through dedifferentiation of mature cells or by mutation to adult stem cells (15). These findings provide evidence that the down-regulation of H3K27me3 may provide a selective advantage for carcinogenesis and tumor progression of ovarian carcinoma.

It has been revealed that decreased protein expression of $\mathrm{H} 3 \mathrm{~K} 27 \mathrm{me} 3$ is significantly correlated with poorer clinical outcome in breast, metastatic prostate, ovarian, and pancreatic cancers $(15,16)$. In contrary, increased protein expression of H3K27me3 is also found to be significantly correlated with adverse clinical outcome in hepatocellular carcinomas and esophageal squamous cell carcinomas $(14,17,18)$. With regard to progression-free survival of ovarian carcinoma, we established that the decreased protein expression of $\mathrm{H} 3 \mathrm{~K} 27 \mathrm{me} 3$ has significant, adverse impact on ovarian cancer patient survival as analyzed by IHC staining. Consistent with previous results obtained by others (16), we found that decreased expression of $\mathrm{H} 3 \mathrm{~K} 27 \mathrm{me} 3$ in ovarian carcinomas was correlated with short- ened patient survival and was a reliable predictor for shortened overall survival by both univariate and multivariate analyses. In addition, we also demonstrated that decreased expression of $\mathrm{H} 3 \mathrm{~K} 27 \mathrm{me} 3$ is a prognostic parameter independent of certain well-established clinical parameters, such as clinical stage and lymph node metastasis for shortened overall survival based on multivariate analyses. In summary our current findings in this study provided evidence that down-regulation of $\mathrm{H} 3 \mathrm{~K} 27 \mathrm{me} 3$ expression may select for a more aggressive phenotype in ovarian carcinoma. Furthermore, it is interesting that our results also showed that ovarian tumor tissues with distant metastasis had significantly decreased expression of H3K27me3 compared with that in ovarian tumor tissues without distant metastasis. It is known that distant metastasis is a significant predictor for patient outcome. These findings also supported that decreased expression of $\mathrm{H} 3 \mathrm{~K} 27 \mathrm{me} 3$ plays an predicted role in ovarian carcinoma.

With regard to the mechanisms by which H3K27 methylation affects tumor behavior, it has been revealed that, as an epigenetic mark, H3K27me3 mediated silencing and repressesed target gene expression (11). Down-regulated of H3K27me3 expression may result in derepression of these silenced genes, therefore, contributing to tumor progression. We know that EZH2 may serve as a histone methyl transferase, and it mediates trimethylation of H3K27 (25). In our previous study, overexpression of EZH2 has been observed in ovarian carcinoma. In addition, knockdown of EZH2 suppresses the invasion of human ovarian cancer cells, which correlates with a decrease in TGF $\beta 1$ expression and an increase in Ecadherin expression. These observed phenotypes correlate with a decrease in the levels of $\mathrm{H} 3 \mathrm{~K} 27 \mathrm{Me} 3$ in these cells (26). EZH2-mediated H3K27 methylation leads to gene silencing may vary among gene targets and among organisms (10), it is simply for us to understand that the potential function of $\mathrm{H} 3 \mathrm{~K} 27 \mathrm{me} 3$ and its underlying mechanism(s), by which, the H3K27me3 exerts its impact on cancer progression may be tumor-type specific and remains elusive. Clearly, further work needs to be done to understand the precise molecular mechanism of H3K27me3 implicated in the development and progression of ovarian carcinoma and other human tumors.

In summary, in present study, we describe expression of H3K27me3 and its impact on patients' clinicopathology/prognosis in a large series of malignant epithelial ovarian tumors. Our results have validated those obtained by others on the roles of $\mathrm{H} 3 \mathrm{~K} 27 \mathrm{me} 3$ expression in ovarian cancer behavior. More significantly, our results support that decreased expression of H3K27me3 may serve as a novel epigenetic marker for detecting the metastatic phenotype in ovarian cancer. In addition, decreased expression of $\mathrm{H} 3 \mathrm{~K} 27 \mathrm{me} 3$ may be critical in the acquisition of a more aggressive biological behavior in ovarian cancer, independent of other clinicopathologic variables.

Acknowledgements: This study was supported by the grants from the Nature Science Foundation of China (No.30772334 and No.81272855), the 973 Project of China (No. 2010CB912802 and 
2010CB529401), the Nature Science Foundation of Guangdong Province (No.S2012010008810) and the Project of Guangdong Science and Technology Agency (No. 2010B060900098).

\section{References}

[1] WINGO PA, RIES LA, ROSENBERG HM, MILLER DS, EDWARDS BK. Cancer incidence and mortality. 1973-1995, a report card for the U.S. Cancer 1998; 82: 1197-1207. http://dx.doi.org/10.1002/(SICI)1097-0142(19980315)82:6<1197::AID-CNCR26>3.0.CO;2-0

[2] JEMAL A, SIEGEL R, WARD E, MURRAY T, XU J, et al. Cancer statistics, 2007. CA Cancer J Clin 2007; 57: 43-66. http://dx.doi.org/10.3322/canjclin.57.1.43

[3] LYNCH HT, CASEY MJ, LYNCH J, WHITE TE, GODWIN AK. Genetics and ovarian carcinoma. Semin Oncol 1998; 25: 265-280.

[4] HEINTZ AP, ODICINO F, MAISONNEUVE P, QUINN MA, BENEDET JL, et al. Carcinoma of the ovary. FIGO 26th Annual Report on the Results of Treatment in Gynecological Cancer. Int J Gynaecol Obstet 95 Suppl 2006; 1: S161-92.

[5] WOLFFE AP, MATZKE MA. Epigenetics: regulation through repression. Science 1999; 286: 481-6. http://dx.doi. org/10.1126/science.286.5439.481

[6] ESTELLER M. Cancer epigenomics: DNA methylomes and histone-modification maps. Nat Rev Genet 2007; 8: 286-298. http://dx.doi.org/10.1038/nrg2005

[7] ESTELLER M. Epigenetics in cancer. N. Engl J. Med 2008; 358: 1148-59. http://dx.doi.org/10.1056/NEJMra072067

[8] STRAHL BD, ALLIS CD. The language of covalent histone modifications. Nature 2000; 403: 41-5. http://dx.doi. org/10.1038/47412

[9] LUND AH, VAN LOHUIZEN M. Epigenetics and cancer. Genes Dev 2004; 18: 2315-2335. http://dx.doi.org/10.1101/ gad. 1232504

[10] CAO R, ZHANG Y. The functions of E(Z)/EZH2-mediated methylation of lysine 27 in histone H3. Curr. Opin. Genet. Dev. 2004; 14: 155-164. http://dx.doi.org/10.1016/j. gde.2004.02.001

[11] CAO R, WANG LJ, WANG HB, XIA L, ERDJUMENTBROMAGE $\mathrm{H}$, et al. Role of histone $\mathrm{H} 3$ lysine 27 methylation in Polycomb-group silencing. Science 2002; 298: 1039-43. http://dx.doi.org/10.1126/science.1076997

[12] SUDO T, UTSUNOMIYA T, MIMORI K, NAGAHARA H, OGAWA K, et al. Clinicopathological significance of EZH2 mRNA expression in patients with hepatocellular carcinoma. Br. J. Cancer 2005; 92: 1754-8. http://dx.doi.org/10.1038/ sj.bjc. 6602531

[13] YONEMITSU Y, IMAZEKI F, CHIBA T, FUKAI K, NAGAI $\mathrm{Y}$, et al. Distinct expression of polycomb group proteins EZH2 and BMI1 in hepatocellular carcinoma. Hum. Pathol. 2009; 40: 1304-11. http://dx.doi.org/10.1016/j.humpath.2009.01.017

[14] CAI MY, HOU JH, RAO HL, LUO RZ, LI M, et al. High Expression of H3K27me3 in Human Hepatocellular Carcinomas
Correlates Closely with Vascular Invasion and Predicts Worse Prognosis in Patients. Mol Med 2011; 17: 12-20.

[15] YU JD, YU JJ, RHODES DR, TOMLINS SA, CAO XH, et al. A polycomb repression signature in metastatic prostate cancer predicts cancer outcome. Cancer Res 2007; 67: 10657-10663. http://dx.doi.org/10.1158/0008-5472.CAN-07-2498

[16] WEI YK, XIA WY, ZHANG ZH, LIU JS, WANG HM, et al. Loss of trimethylation at lysine 27 of histone $\mathrm{H} 3$ is a predictor of poor outcome in breast, ovarian, and pancreatic cancers. Mol. Carcinog 2008; 47: 701-706. http://dx.doi.org/10.1002/ $\underline{\text { mc. } 20413}$

[17] TUNG HJ, JIN JS, SUN GH, HSU HS, CHEN BH, et al. Prognostic significance of global histone modifications in resected squamous cell carcinoma of the esophagus. Mod. Pathol 2009; 22: 252-260. http://dx.doi.org/10.1038/ modpathol.2008.172

[18] HE LR, LIU MZ, LI BK, RAO HL, LIAO YJ, et al. Prognostic impact of $\mathrm{H} 3 \mathrm{~K} 27 \mathrm{me} 3$ expression on locoregional progression after chemoradiotherapy in esophageal squamous cell carcinoma. BMC Cancer 2009; 9: 461. http://dx.doi. org/10.1186/1471-2407-9-461

[19] XIE D, SHAM JST, ZENG WF, LIN HL, CHE LH, et al. Heterogeneous expression and association of $\beta$-catenin, p16 and c-myc in multistage colorectal tumorigenesis and progression detected by tissue microarray. Int J Cancer 2003; 107(6): 896-902. http://dx.doi.org/10.1002/ijc.11514

[20] XIE D, ZENG YX, WANG HJ, WEN JM, TAO Y, et al. Expression of cytoplasmic and nuclear Survivin in primary and secondary human glioblastoma. Br J Cancer 2006; 94: 108-14. http://dx.doi.org/10.1038/sj.bjc.6602904

[21] JONES PA, BAYLIN SB. The fundamental role of epigenetic events in cancer. Nat Rev, Genet 2002; 3: 415-28.

[22] LEE TI, JENNER RG, BOYER LA, GUENTHER MG, LEVINE SS, et al. Control of developmental regulators by Polycomb in human embryonic stem cells. Cell 2006; 125: 301-313. http://dx.doi.org/10.1016/j.cell.2006.02.043

[23] BRACKEN AP, DIETRICH N, PASINI D, HANSEN KH, HELIN K. Genomewide mapping of Polycomb target genes unravels their roles in cell fate transitions. Genes Dev 2006; 20: 1123-1136. http://dx.doi.org/10.1101/gad.381706

[24] MARGUERON R, TROJER P, REINBERG D. The key to development: interpreting the histone code? Curr Opin Genet Dev 2005; 15: 163-176. http://dx.doi.org/10.1016/j. gde.2005.01.005

[25] TONINI T, D’ANDRILLI G, FUCITO A, GASPA L, BAGELLA L. Importance of Ezh2 polycomb protein in tumorigenesis process interfering with the pathway of growth suppressive key elements. J. Cell. Physiol 2008; 214: 295-300. http://dx.doi. org/10.1002/jcp.21241

[26] RAO ZY, CAI MY, YANG GF, HE LR, MAI SJ, et al. EZH2 supports ovarian carcinoma cell invasion and/or metastasis via regulation of TGF-betal and is a predictor of outcome in ovarian carcinoma patients. Carcinogenesis. 2010; 31: 1576-83. http://dx.doi.org/10.1093/carcin/bgq150 